\title{
Robotics in cardiac surgery: The emperor's new clothes
}

\author{
Ralph J. Damiano Jr, MD
}

See related articles on pages 562 and 710.
From the Washington University in St Louis School of Medicine/Barnes Jewish Hospital, Division of Cardiothoracic Surgery, St Louis, Mo.

Received for publication Aug 3, 2006; accepted for publication Aug 24, 2006.

Address for reprints: Ralph J. Damiano Jr, MD, Washington University in St Louis School of Medicine/Barnes Jewish Hospital, Division of Cardiothoracic Surgery, 1 Barnes-Jewish Hospital Plaza, Suite 3108, Queeny Tower Campus Box 8234, St Louis, MO 63110 (E-mail: damianor@ wustl.edu).

J Thorac Cardiovasc Surg 2007;134:559-61 $0022-5223 / \$ 32.00$

Copyright @ 2007 by The American Association for Thoracic Surgery

doi:10.1016/j.jtcvs.2006.08.026
"But he has nothing on at all," said a little child at last. "Good heavens! listen to the voice of an innocent child," said the father, and one whispered to the other what the child had said. "But he has nothing on at all," cried at last the whole people. That made a deep impression upon the emperor, for it seemed to him that they were right; but he thought to himself, "Now I must bear up to the end." And the chamberlains walked with still greater dignity, as if they carried the train which did not exist.

The Emperor's New Clothes

Hans Christian Andersen, 1837

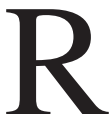

obotic cardiac surgery was introduced clinically almost 10 years ago. In 1998, the first mitral and coronary artery bypass procedures were performed in Europe. ${ }^{1-3}$ The first robotic coronary artery bypass grafting in North America was performed later the same year. ${ }^{4}$ Although this has been an exciting technology, it is time to look back after almost a decade of clinical experience and objectively examine whether it has lived up to its potential. In many ways, robotics has been a promise unfulfilled. The article in this issue of the Journal by De Canniere and coauthors ${ }^{5}$ illustrates some of the difficulties in applying robotic instrumentation to cardiac microsurgery.

Robotic instrumentation was introduced in the hope that it would enhance surgical ability and enable endoscopic microsurgery. Cardiac surgery was believed to be an ideal application for this advanced technology, because standard handheld endoscopic instruments, although adequate for excisional and resectional therapy, did not possess the requisite dexterity for reconstructive microsurgery. There was great hope that it would enable minimally invasive, completely endoscopic coronary bypass grafting.

Early work in the field demonstrated that the technology enabled endoscopic coronary bypass grafting through standard incisions on the stopped heart on cardiopulmonary bypass. ${ }^{4,6}$ A number of groups, principally in Germany, began to experiment with totally endoscopic coronary bypass grafting on the arrested heart. All of these cases used the Heartport System and the DaVinci robot by Intuitive Surgical (Sunnyvale, Calif). The first case was performed by Loulmet and colleagues in $1999 .{ }^{3}$ One of the pioneering groups in Leipzig reported that 22 patients underwent single-vessel left internal thoracic artery to the left anterior descending artery bypass grafting with the DaVinci system. ${ }^{7}$ The conversion rate was $18 \%$. The average crossclamp time was 68 minutes, with an average cardiopulmonary bypass time of more than 2 hours. The 3-month patency was excellent. In a larger experience from Frankfurt, 45 cases were reported using similar technology, 8 of which had double-vessel coronary bypass grafting. ${ }^{8}$ Crossclamp times were similar: $61 \pm 16$ minutes for single-vessel bypass grafting and $99 \pm 55$ minutes for double-vessel bypass grafting. Mean cardiopulmonary bypass times were 136 and 
197 minutes, respectively, for single- and double-coronary bypass grafting. Although the conversion rate was $22 \%$, the patency was excellent. There were no apparent advantages of this approach over traditional coronary surgery, and complication rates were relatively high, with a $2 \%$ incidence of myocardial infarction and a $2 \%$ rate of stroke and aortic dissection. The average length of stay for patients undergoing a single-vessel coronary bypass grafting was $8.6 \pm 2.7$ days. Unfortunately, single- and double-vessel coronary bypass graft procedures with 2- to 4-hour bypass times were not comparable to off-pump or even traditional on-pump surgery. Because this operation put patients at risk of long bypass and crossclamp times for purely cosmetic benefit, it has not been performed with any frequency in the United States.

The only reasonable application left for robotic systems has been endoscopic coronary bypass grafting on the beating heart. The advent of off-pump coronary bypass grafting techniques made this the approach of choice for limited coronary artery disease in many centers. The early experience with the DaVinci system on the beating heart was not positive. As of August 2002, it was reported that 100 closed-chest beating heart procedures were performed with a conversion rate of $25 \%$ to $50 \%$. There was no objective angiographic control available at the time of this early report by Falk and colleagues. ${ }^{9}$ This led Dogan and colleagues, ${ }^{8}$ in a report in the same year, to state "Despite attempts to perform totally endoscopic with the DaVinci ${ }^{\mathrm{TM}}$ system on the beating heart, the success rates of such procedures remains low." It was thought that direct comparison with the minimally invasive direct coronary artery bypass technique would be possible only when this became a reproducible and safe operation.

In the present report, the authors present the largest series of endoscopic coronary bypass procedures performed off cardiopulmonary bypass. A total of 111 patients underwent this procedure between September 1998 and November 2002 , with a $33 \%$ conversion rate. This was most commonly because of the inability to locate or dissect the left anterior descending coronary artery or the anastomotic site bleeding. There were also a number of patients with inadequate stabilization. Unfortunately, only 38 of these patients had postoperative angiography, with a patency rate of $92 \%$. The mortality in this group was $2.7 \%$, and target vessel reintervention at 6-month follow-up was $4 \%$. No attempt was made to compare these results with either open coronary bypass grafting or minimally invasive direct coronary artery bypass procedures. Another weakness of this report was that only 6-month follow-up was presented, except for a randomly selected cohort of 100 patients in whom longer follow-up was available.

Despite the authors' claims, this report does not demonstrate in any way that endoscopic coronary artery by- pass grafting is safe or effective. For this to be demonstrated, they would have to show that it gave outcomes comparable to those of traditional open or other minimally invasive off-pump techniques. In fact, this has not been documented in any of the innumerable publications on robotics. Instead, this report demonstrates the limited applicability of this technology for coronary bypass grafting, even in experienced centers. These 228 patients represented a small fraction $(<1 \%)$ of the total coronary bypass grafting experience at these large university centers. Despite this highly selected cohort of patients with principally single-vessel coronary disease, there was still a $2.7 \%$ mortality and a high conversion rate. Previously reported hospital lengths of stays after robotic surgery from these institutions also have been long.

The relatively unimpressive results seen with robotics may partly be explained by the limitations of the technology, particularly on the beating heart. In 2003, Jacobs and colleagues ${ }^{10}$ reported the results of using an endoscopic trainer developed to simulate beating heart conditions. Twenty subjects were asked to touch objects manually or robotically with the DaVinci system. The object was at rest or allowed to move slightly at a frequency of 35 to $90 \mathrm{~Hz}$ simulating off-pump coronary bypass grafting. Robotic assistance slowed task completion by 2.9 times. In prior studies, robotics also have been uniformly shown to slow the completion of gross motor skills. ${ }^{11,12}$ More worrisome is that the error rate with robotics was approximately 6 times higher than the manual group when there was any movement. ${ }^{10}$

The true conclusion to be taken from this publication and the numerous others in the literature is that after approximately a decade of use in the operating room, there has been no demonstration of any clinical value of robotic assistance for coronary bypass grafting. There has not been one report in the literature that has demonstrated any statistically significant improvement in outcomes, length of stay, or mortality with these expensive systems. At the present time, the only plausible procedure for which robotics is essential (totally endoscopic coronary artery bypass grafting on the beating heart) has proven to be so difficult that it has not achieved any widespread applicability. It is time to recognize that robotics are no longer a promising new technology but instead a technology that has been tried and has failed to demonstrate any clinical value, outside of its questionable use for marketing. If endoscopic robotically assisted coronary bypass grafting is ever to be truly useful, it will likely require a major reengineering of these systems, markedly decreased costs, and the development of other parallel technology, such as anastomotic devices, better endoscopic stabilizers, and perhaps image guidance systems. However, at the present time, this emperor truly has no clothes. 


\section{References}

1. Carpentier A, Loulmet D, Aupecle B, Kieffer JP, Tournay D, Guibourt $\mathrm{P}$, et al. Computer assisted open-heart surgery. First case operated on with success. C R Acad Sci II. 1998;321:437-42.

2. Falk V, Walther T, Autschbach R, Diegeler A, Battellini R, Mohr FW. Robot assisted minimally invasive mitral valve solo surgery. J Thorac Cardiovasc Surg. 1998;118:470-1.

3. Loulmet D, Carpentier A, d'Attellis N, Berrebi A, Cardon Cy, Ponzio $\mathrm{O}$, et al. Endoscopic coronary artery bypass grafting with the aid of robotic assisted instruments. J Thorac Cardiovasc Surg. 1999;118:410.

4. Damiano RJ Jr, Ehrman WJ, Ducko CT, Tabaie HA, Stephenson ER, Kingsley CP, et al. Initial U.S. clinical trial of robotically-assisted endoscopic coronary artery bypass grafting. $J$ Thorac Cardiovasc Surg. 2000;119:77-82.

5. De Canniere D, Wimmer-Greinecker G, Cichon R, Gulielmos V, Van Praet F, Seshadri-Kreaden U, et al. Feasibility, safety and efficacy of totally endoscopic coronary artery bypass grafting: multicenter European experience. J Thorac Cardiovasc Surg. 2007;133:710-6.

6. Reichenspurner H, Damiano RJ, Mack M, Boehm DM, Gulbins H, Meisner B, et al. Experimental and first clinical use of the voice-controlled and computer-assisted surgical system Zeus for endoscopic coronary artery bypass grafting. J Thorac Cardiovasc Surg. 1999;118:11-6.

7. Falk V, Diegeler A, Walther T, Banusch J, Brucerius J, Raumans J, et al. Total endoscopic computer enhanced coronary artery bypass grafting. Eur J Cardiothorac Surg. 2000;17:38-45.

8. Dogan S, Aybek T, Andreben E, Byhahn C, Mierdl S, Westphal K, et al. Totally endoscopic coronary artery bypass grafting on cardiopulmonary bypass with robotically enhanced telemanipulation: report of forty-five cases. J Thorac Cardiovasc Surg. 2002;123: 1125-31.

9. Falk V, Jacobs S, Gummert JF, Walthert T, Mohr FW. Computerenhanced endoscopic coronary artery bypass grafting: the da Vinci experience. Semin Thorac Cardiovasc Surg. 2003;15:104-11.

10. Jacobs S, Holzhey D, Kiaii B, Onnasch JF, Walther T, Mohr FW, et al. Limitations for manual and telemanipulator-assisted motion tracking-implications for endoscopic beating-heart surgery. Ann Thorac Surg. 2003;76:2029-36.

11. Diodato MD, Prasad SM, Klingensmith ME, Damiano RJ Jr. Robotics in surgery. Curr Prob Surg. 2004;41:743-810.

12. Prasad SM, Manair HS, Soper NJ, Damiano RJ Jr, Klingensmith ME. The effect of robotic assistance on learning curves for basic laparoscopic skills. Am J Surg. 2002;183:702-7.

\section{JTCVS On-Line Manuscript Submission and Review}

The Journal of Thoracic and Cardiovascular Surgery requires authors and reviewers to submit all new and revised manuscripts and reviews via Editorial Manager. Point your browser to http://jtcvs.editorialmanager.com, log in as author or reviewer (as appropriate), and follow the instructions provided.

To retrieve your username and password, click "Forget your password?" on the Editorial Manager log-in page.

If you have questions or experience problems uploading your manuscript or review, please contact the editorial office:

Telephone: $215-762-1854$

E-mail: jtcvs@drexelmed.edu 